\title{
O FAMILIAR ACOMPANHANTE NO CUIDADO AO ADULTO HOSPITALIZADO NA VISÃO DA EQUIPE DE ENFERMAGEMa
}

\author{
CharlineSZARESKI ${ }^{b}, M_{\text {argrid BEUTER }}^{c}, C^{2}$ Célia M aria BRONDANI
}

\section{RESUM 0}

0 estudo teve como objetivo descrever e analisar a inserção do familiar acompanhante no processo de cuidar do doente adulto hospital izado na ótica da equipe de enfer magem. T rata-se de uma pesquisa qual itativa, real izada em uma unidade de clínica médica adulto, de um hospital universitário do interior do Rio G rande do Sul, com a participação de 14 membros da equipe de enfermagem. Para a produção dos dados, utilizou-se o M étodo Criativo e Sensível (M CS). Na análise dos dados for am utilizados al guns pressupostos da análise de discurso francesa. Os temas desvelados foram: a presença indispensável do familiar acompanhante; aspectos relacionados à singularidade do acompanhante; a falta de comprometimento do acompanhante. Conclui-se que é importante o reconhecimento da singularidade dos acompanhantes pelos profissionais de enfermagem, para que possam compreender suas idiossincrasias e assim inseri-los ou não nos cuidados, aceitando os limites e as possibilidades de cada um no processo de cuidar do doente.

D escritores: H ospital ização. A companhantes de pacientes. Família. E quipe de enfer magem.

\section{RESUMEN}

E ste estudio tuvo como objetivo describir y analizar la inserción del familiar acompañante en el proceso de cuidado del enfermo adulto hospitalizado bajo la óptica del equipo de enfermería. Se trata de una investigación cual itativa, realizada en una unidad de dínica médica adulta, de un hospital universitario del interior del R io G rande do Sul, B rasil, con la participación de 14 miembros del equipo de enfermería. Para la producción de los datos, se utilizó el M étodo Creativo y Sensible L os temas surgidos fuer on: Ia presencia indispensable del familiar acompañante; aspectos relacionados con la singularidad del acompañante; la falta de comprometimiento del acompañante. Se concluye que es importante el reconocimiento de la singularidad de los acompañantes por los profesionales de enfermería, para que puedan comprender sus idiosincrasias y, así, inser tarlos o no en los cuidados, aceptando los límites y las posibilidades de cada uno en el proceso de cuidado del enfermo.

D escriptores: H ospitalización. A compañantes de pacientes. Familia. G rupo de enfermería.

Título: E I familiar acompañante en el cuidado del adulto hospitalizado en la óptica del equipo de enfermería.

\section{ABST RACT}

T he study described and analyzed the insertion of family companions in giving care to a hospitalized adult according to a nursing team. It is a qualitative research, carried out in an adult outpatient's facility of a university hospital in R io $\mathrm{G}$ rande do Sul, B razil, with 14 members of a nursing team. Creative and SensitiveM ethod was used for data production. In order to analyz e data, some presuppositions of the $F$ rench discourse analysis w ere a pplied. The themes unveiled were: the compul sory presence of a family companion; aspects of the singularity of the companion; and the lack of companion's commitment. The recognition of companions' singularity by nursing professionals is important to understand their idiosyncrasy, making them part or not of the care process, accepting limits and possibilities of each in giving care to the patient.

D escriptors: H ospitalization. Patient escort service Family. N ursing team.

T itle: Family companion in the care with a hospitalized adult in the perspective of the nursing team.

\footnotetext{
a E studo elaborado com base na dissertação de M estrado apresentado em 2009 ao Programa de Pós-G raduação em Enfermagem (P PG Enf) da U niversidade Federal de Santa M aria (U F SM ), Santa M aria, Rio G rande do Sul, Brasil.

${ }^{b}$ M estre em Enfermagem, Enfermeira da Prefeitura M unicipal de Caxias do Sul, Rio G rande do Sul, Brasil.

' D outora em Enfermagem, Professora Adjunta do D epartamento de Enfermagem e do PPGEnf da UF SM, Santa M aria, Rio Grande do Sul, Brasil.

`M estre em Enfermagem, Enfermeira do H ospital U niversitário de Santa M aria, Rio Grande do Sul, Brasil.
} 


\section{INT RODUÇÃO}

A permanência de familiares acompanhantes junto ao doente hospitalizado tem exigido transformações na prática da equipe de enfermagem. Deste modo, a equipe necessita adaptar-se a esta situação alterando atitudes, posturas, demonstrando receptividade frente à presença do acompanhante no cotidiano do cuidado. 0 acolhimento do doente e do seu familiar pela equipe é importante, pois a doença e a hospital ização representam uma condição difícil na vida do ser humano(1).

U m estudo considera a importância da presença dos familiares durante a hospitalização do doente adulto, sejam el es acompanhantes ou visitantes, justificando que quando ele adoece, apresenta tendência a desenvolver maior dependência e apego dos familiares, necessitando ter, próximo de si, pessoas que Ihe transmitam atenção e confiança ${ }^{(2)}$. Portanto, é benéfica a companhia de pessoas que possibilitem ao doente a exposição de seus sentimentos e emoções, bem como, 0 ajudem a controlar suas ansiedades, medos e fantasias.

A equipe de enfermagem tende, quando a família está presente no ambiente hospitalar, a preocupar-se mais em mantê-la obediente às normas e rotinas da instituição, esper ando que cumpra com suas obrigações de cuidar e não interfira nas atividades da enfermagem. Entretanto, compete ao enfer meiro assegurar o direito da presença da família junto ao doente incentivando a sua participação no processo de cuidar, de forma constante, na condição de acompanhante ou de forma esporádica como visitante, quando esta é desejada pelo doente.

Iniciativas, como a Política $\mathrm{N}$ acional de $\mathrm{Hu}$ manização do M inistério da Saúde ${ }^{(3)}$, têm proposto a adoção de novas práticas nos espaços públicos dos hospitais, com o direito a acompanhante para pacientes adultos internados, e a visita aberta aos familiares no hospital, fato este que visa à humanização do cuidado e à aproximação da família junto ao doente hospitalizado. Verifica-se que esse é um processo lento, visto que as instituições ainda não possuem uma estrutura física e organizacional propícia para acolher o familiar. Diante dessa situação, o hospital tende a ser percebido como um ambiente frio, impessoal, gerador de dor e sofrimento, pelo doente e sua família(4).

A aprovação de leis e decretos que regulamentam 0 direito à permanência de acompanhante pa- ra alguns grupos específicos tem possibilitado a humanização do ambiente hospitalar. De acordo com as L eis $n=8.069 / 90^{(5)}$, $n$ ㅇ 10.741/ $03^{(6)}$ e $n^{\circ}$ $11.108 / 05^{(7)}$, a criança, 0 adolescente, 0 idoso e a parturiente têm direito a acompanhante durante a hospitalização. Em relação ao adulto, a Política Nacional de Humanização da Saúde recomenda a presença do acompanhante, no entanto, a per missão deste fica na dependência de acordos e liberações institucionais cujo cumprimento, na maioria das vezes, é decidido pelo enfermeiro.

Para que ocorra uma aproximação entre profissionais de enfermagem e a família no cenário hospitalar, é necessário que o enfermeiro procure incentivar a interação da equipe com o familiar acompanhante, no qual ambos se respeitem, troquem experiências e aprendam mutuamente ${ }^{(8)}$. No entanto, na prática essa aproximação não tem sido fácil, pois existe resistência, por parte dos profissionais de saúde e das instituições, quanto à presença e à participação da família nos cuidados durante a hospitalização.

F rente à problemática apresentada, el egeu-se como questão norteadora do estudo: como a equipe de enfermagem compreende a inserção do familiar acompanhante no cenário do cuidado de enfermagem hospitalar? Para elucidar esta questão traçou-se o seguinte objetivo: descrever e analisar a inserção do familiar acompanhante no processo de cuidar do doente adulto hospitalizado na ótica da equipe de enfermagem.

\section{MET ODOLOGIA}

T rata-se de uma pesquisa qualitativa do tipo descritivo-exploratória, desenvolvida em uma unidade de clínica médica de um hospital universitário do interior do Rio Grande do Sul( ${ }^{(9)}$. Esta unidade distingue-se pelo atendimento a pessoas portadoras de doenças crônicas que exigem muitos cuidados de enfermagem, motivo pelo qual a presença de acompanhantes é comum. Os doentes e seus familiares geralmente são procedentes de outras cidades do estado.

Os sujeitos do estudo foram 14 profissionais de enfermagem, sendo quatro enfermeiros, nove técnicos de enfer magem e um auxiliar de enfermagem. Os participantes caracterizaram-se por treze mulheres e um homem; a faixa etária predominante foi de 31 a 40 anos para dez sujeitos; 0 estado civil foi de oito casados e seis solteiros; e o tempo 
de atuação profissional teve predomínio de um a cinco anos para doze sujeitos.

Para a produção dos dados, utilizou-se o M étodo Criativo-Sensível (MCS), por meio do desenvolvimento de Dinâmicas de Criatividade e Sensibilidade (DCS). As DCS combinam procedimentos de coleta de dados típicos da pesquisa qualitativa tradicional (observação, entrevista e discussão de grupo) com as produções artísticas. E mbora a concepção grupal imanente a DCS, seja de pluralidade, a singularidade de cada participante é preservada pelo espírito democrático e participativo. Dessa forma, os sujeitos sentem-se confortáveis para socializar suas experiências, gerando materiais empíricos eval idando dados e análises já produzidas ${ }^{(10)}$.

A realização das dinâmicas compreende cinco momentos. 0 primeiro corresponde à preparação do ambiente e acolhimento dos participantes. 0 segundo diz respeito à apresentação do grupo e explicação da sistemática do trabalho. 0 terceiro consiste na produção artística individual ou coletiva. No quarto momento, os participantes apresentam suas produções e coletivizam as suas experiências. 0 quinto momento envolve a análise preliminar e validação dos dados ${ }^{(10)}$.

N esse estudo foram realizadas três dinâmicas. Cada dinâmica teve uma média de participação de cinco profissionais. A primeira dinâmica, "Árvore do Conhecimento", teve como questão geradora de debate: qual o espaço ocupado pelo familiar acompanhante no cuidado ao doente hospital izado? N esta dinâmica, o desenho de uma árvore foi fixado à parede a fim de que os participantes realizassem uma analogia entre as necessidades da árvore para se desenvolver e as do familiar acompanhante no cuidado ao doente hospitalizado.

A segunda dinâmica foi "Costurando Estórias" com a questão geradora de debate: em que situações o familiar acompanhante participa do cuidado ao doente hospitalizado? Os participantes do estudo escreveram em folhas de papel A4 as suas vivências e experiências com os familiares acompanhantes no cuidado ao doente hospitalizado, e posteriormente compartilharam-nas com o grupo.

A terceira dinâmica foi o "AImanaque" com a questão geradora de debate: de que modo o familiar acompanhante contribui no cuidado e na práxis (atividades) da enfermagem? Os participantes do estudo elaboraram sua produção artística individual, a partir do questionamento feito ao grupo, utilizando as técnicas de recorte e colagem.
Para a análise e interpretação dos dados, foram utilizados alguns pressupostos da análise de discurso francesa e discutidos com base no referencial teórico relacionado à temática. A análise de discurso consiste na análise de unidades texto para além da análise da frase, possibilitando a leitura dos interdiscursos e valorizando a relação de sentidos na inter ação com o outro, o que leva em consider ação a sua historicidade ${ }^{(11)}$.

$\mathrm{Na}$ análise de discurso, os dispositivos analíticos são utilizados para desvelar os sentidos de uma deter minada discursividade. Os dispositivos considerados nesse estudo foram: a paráfrase, a polissemia e a metáfora ${ }^{(11)}$.

A paráfrase consiste em diferentes formulações do mesmo dizer sedimentado, retornando aos mesmos espaços do dizer. A polissemia caracteriza-se pela emergência do diferente, rompendo com a repetição. Assim, considera-se que o discurso se constrói da tensão entre a paráfrase (mesmo) e a polissemia (diferente). A metáfora representa a transferência de significado de uma palavra pela outra(11).

Com o uso desses dispositivos analíticos é possível superar as ilusões que 0 analista constrói, ao entrar em contato com o material empírico, conferindo o rigor científico necessário e evitando, assim, que se limite a descrever os dados encontra$\operatorname{dos}^{(11)}$.

A análise de discurso é um processo que se inicia com o estabelecimento do corpus de análise. N este estudo, os relatórios das DCS constituíram o corpus a ser analisado. I nicialmente, realizou-se a análise denominada horizontal, que visa a não exaustividade do objeto empírico, visto que todo discurso se estabelece dos movimentos dialógicos dos enunciantes, em que um discurso anterior aponta para o outro. Feito isso, partiu-se para a análise denominada vertical, que busca atingir a exaustividade do objeto, o sentido das palavras e das manifestações discursivas ${ }^{(11)}$.

Com o objetivo de organizar e facilitar a análise dos dados foram elaborados quadros analíticos para cada dinâmica. E stes apresentaram os seguintes componentes: a situação existencial dos profissionais de enfermagem, que emergiram no interior das dinâmicas, o tema gerador, o subtema, a recodificação temática e o comentário analítico do processo interpretativo.

A pesquisa foi realizada mediante autorização da instituição, junto à Direção de Ensino, 
Pesquisa e Extensão do hospital (DEPE), protocolo no 136, e aprovação pelo Consel ho de É tica em Pesquisa da instituição por meio do processo no 23081.018612/ 2008-67 e pelo Certificado de Apresentação para A preciação Ética (CAAE) no 0259.0.000-08, em atendimento à Resolução 196/ 96 do Conselho Nacional de Saúde ${ }^{(12)}$. 0 Termo de Consentimento Livre e Esclarecido (T CLE) foi assinado pelos participantes após os devidos esclarecimentos, em relação aos objetivos do estudo, riscos e benefícios.

A fim de preservar a identidade dos sujeitos participantes do estudo, os discursos foram identificados com a letra "E" para enfermeiras, as letras "T E" para os técnicos de enfermagem e uma auxiliar de enfermagem, seguidos de números arábicos. D evido à participação de apenas uma auxiliar de enfermagem, esta recebeu a mesma identificação dos técnicos de enfermagem, garantindo assim o seu sigilo.

\section{RESULTADOS E DISCUSSÃO}

As vivências e experiências da equipe de enfermagem com os familiares acompanhantes foram retratadas e problematizadas coletivamente no interior das dinâmicas. A partir da análise e interpretação destas vivências emergiram os temas: a presença indispensável do familiar acompanhante; aspectos relacionados à singularidade do acompanhante e a falta de comprometimento do familiar acompanhante.

\section{A presença indispensável do familiar acompanhante}

Pode-se observar na enunciação dialógica dos sujeitos, na dinâmica Árvore do Conhecimento, a importância da presença de um membro da família durante a hospital ização ao referirem-se aos doentes que não possuem acompanhantes, conforme os discursos a seguir.

É tão triste ver aquele paciente que está sozinho. Tu não consegues dar atenção suficiente para ele T u não consegues entrar muitas vez es no quarto. E les não têm ninguém [ ...] a família mora longe (T E 2).

Tem muitos [ refere-se aos pacientes] para gente cuidar. Às vezes, a gente ali, não consegue dar aque la atenção, como a que o familiar poderia dar [ ...] ( $T E 1)$.
Os membros da equipe de enfermagem refle tem sobre a presença do familiar como uma forma de proporcionar companhia ao doente, diminuindo a solidão inerente à hospitalização, apoiando0 , escutando-0, consolando-0, assim somando com o trabalho da equipe.

0 discurso da TE 2 revela sentimento de solidariedade com o sofrimento do doente que está sozinho, pois sua convivência diária com esta situação é geradora de tristeza. T ambém remete à sensação de impotência, pois ela não consegue dar atenção que desejaria para os doentes que se encontram na condição de sem familiares, sem visitas.

A necessidade da companhia de um familiar na internação do doente adulto é discutida em estudo ao destacar que na hospitalização os sentimentos de ansiedade e insegurança, iner entes ao processo de adoecimento humano, podem ser potencializados ${ }^{(13)}$. I sso ocorre porque o doente inter nado é obrigado a afastar-se do seu lar, da família, dos amigos, do trabalho, e consequentemente altera seus hábitos e rotinas. Logo, a presença do acompanhante é importante para manter o elo entre o doente hospitalizado e o seu cotidiano familiar e social.

0 discurso parafrásico da enfermeira durante a dinâmica Almanaque desvela a importância do familiar no dia a dia no cuidado ao doente:

[ ...] E u acho que a família éimportante! E u acho que se consegue melhores resultados quando a família está inserida com o paciente E stá inserida nos cuidados. $M$ uitas vezes, o paciente não aceita o tratamento. Vai fazer a medicação, elenão quer essa medicação. T u vai orientar para o banho, ele não quer aquele banho. $\mathrm{E} \mathrm{n}$ tão o familiar estando junto consegue cativar melhor (E 4).

A enfermeira em seu discurso relata que a família comprometida com o cuidado ao doente possibilita uma melhor adesão e colaboração do doente ao tratamento. Revela ainda que a atuação do familiar como mediador entre a equipe de enfermagem e o doente na realização do cuidado permite mel hores resultados para a sua recuperação.

A família, por suas características de proximidade e convivência, possui maiores condições de acompanhar o processo de saúde-doença de seus membros do que os próprios profissionais. Por sua intimidade, os membros da família são capazes de identificar sinais de doença que, para outras pes- 
soas, podem passar despercebidos. Sendo assim, é comum 0 acompanhante ser o primeiro a identificar as alterações no seu quadro clínico(14).

U ma parceria entre familiares e equipe de enfermagem é recomendável. Assim, a equipe orienta 0 acompanhante quanto às atividades em que ele poderá participar e auxiliar ${ }^{(15)}$. Seguindo esta linha de pensamento, o discurso a seguir, na dinâmica Almanaque confirma porque a presença do familiar acompanhante é indispensável para o doente:

[ ...] E ntão, o familiar é um ponto chave que a gente gostaria que todos os pacientes [ ...] todos os pacientes tivessem um familiar. U m ente querido para poder cuildá-Ios, né! E estar junto com a gente. Porque a gente, a enfermagem, a medicina, a fisioterapia, a nutrição, sozinhos não conseguem resolver o problema, se a família não estiver inserida (E 4).

0 discurso metafórico e polissêmico da enfermeira enfatiza o desejo de que "todos os pacientes" tenham um familiar presente para cuidá-los, em parceria com a enfermagem e a equipe multiprofissional. Para esta profissional é essencial a cumplicidade do familiar com os profissionais da saúde para a resolução dos problemas inerentes da hospitalização do doente.

\section{Aspectos relacionados à singularidade do acompanhante}

Os discursos no âmbito da dinâmica Costurando E stórias e A Imanaque retratam como a singularidade de cada acompanhante afeta a sua inserção no cuidado ao doente:

E u acho que depende muito do acompanhante! P orque cada pessoa é difer ente U mas são mais nervosas eque rem ajudar enão sabem. 0 utras são da área da saúdee querem fazer. E ntão, depende muito de cada acompanhante! (E 2).

A ajuda deles no cuidado é muito importantel Quando eles não agitam! Q uando eles não se agitam. P orque quando eles se agitam e ficam nervosos, a gente também entra naquele clima, né. E ntão a gente precisa deles assim [ ...] mais calmos (T E 8).

Os discursos polissêmicos revelam que cada acompanhante tem um modo particular de agir e reagir ao deparar-se com o cuidado ao doente. As- sim, al guns gostariam de auxiliar no cuidado, mas não têm condições emocionais para suportar tal situação. Eles ficam nervosos, agitados e perturbam o serviço, enquanto outros mais familiarizados com o ambiente hospitalar sentem-se mais seguros para ajudar no cuidado ao familiar. $\mathrm{N}$ a discussão grupal, ficou evidenciada a importância da inserção do familiar no cuidado ao doente, desde que o seu estado emocional não desestabilize o trabal ho da equipe de enfer magem.

Deste modo, o profissional de enfermagem deve estar ciente da singularidade de cada acompanhante, exercendo seu trabalho pautado na solidariedade, colaborando para o restabelecimento do doente e no alívio do seu sofrimento e dos seus familiares, portanto, promovendo a saúde do grupo familiar ${ }^{(16)}$

As enunciações dialógicas dos membros da equipe enfermagem, durante a discussão coletiva na dinâmica Costurando E stórias, demonstraram como a singularidade dos acompanhantes influencia na sua inserção no cuidado:

[ ...] E ntão a gente tem " $\mathrm{n}$ " tipo de acompanhantes! "N" tipos de acompanhantes aqui dentro, né! E ntão, acho que parte muito deles [ ...] a vontade de aprender, né! P arte muito deles! U ns querem mais, outros querem menos e outros não querem se comprometer. $M$ as, na maioria das vezes, são pessoas, tem pessoas receptivas que querem! (E 3).

\section{[ ...] P orque tem familiar que não ajuda! (T E 7).}

É, mas tem aqueles que trazem o paciente pra baixo. Tem! É nítido! Q uando tem um familiar com ele, ele está bem. Q uando tem outro familiar, ele se fecha, se deprime (TE 6).

N ão só deprime como fica agressivo também! (T E 4).

0 discurso metafórico da enfermeira (E 3) revela que na unidade onde trabal ha tem " $n$ " tipos de acompanhantes, demonstrando a diversidade de familiares presentes no ambiente hospitalar.

D este modo, o diálogo polissêmico entre a enfermeira e os técnicos de enfer magem revela que a inserção dos acompanhantes no cuidado é influenciada pela singularidade de cada sujeito. De modo geral, a iniciativa parte dos acompanhantes que questionam e procuram envolver-se nos cuidados. No entanto, há aqueles que não querem se envolver, assim como há outros que prejudicam o doen- 
te em sua recuperação, pois a sua presença, além de deixá-lo deprimido, torna-o agressivo.

\section{A falta de comprometimento do acompanhante}

A equipe de enfermagem deposita confiança no acompanhante e esper a que el e cumpra seu papel de vigilante junto ao doente. Quando o acompanhante não corresponde a esta expectativa, ocorre uma resistência por parte dela em aceitar a permanência do acompanhante. Desse modo, a equipe usa o seu poder para decidir pela permanência (ou não) deste ou daquele familiar no cenário hospitalar ${ }^{(17) .}$

O diálogo travado, no interior da dinâmica A Imanaque, revela que a equipe de enfermagem perde a confiança nos acompanhantes, quando eles não colaboram com o cuidado:

[ ...] Às vezes, tu entra ali [ refere-se ao quarto] . N ão viram 0 coitado nunca [ refere-se ao paciente]. $N$ ão dão uma água para eletomar. N ão ol ham nem nos ol hos da pessoa. E ntão, às vezes, tu confia naquela pessoa. P orque está como acompanhante. T u confia na pessoa! E ntão demora mais tempo para tu chegar lá e tu vê aquela cena. P or quetu largou? P orque tu confiou naquele acompanhanteque estava ali para dar uma arrumada? T irar uma coberta. T u chega ali ele está suando, tapado [ refere-se ao doente] . E a pessoa está ali [ acompanhante] (TE 9).

0 discurso do técnico de enfermagem revela que ele, muitas vezes, deposita a responsabilidade do cuidado no acompanhante, pois alguns assumem estes cuidados, os quais são vistos pela equipe como comprometidos, enquanto que os demais que não assumem são recriminados ou tidos como descomprometidos. D estaca-se que a responsabilidade do cuidado é da equipe de enfermagem, e não deve ser delegada ou exigida dos acompanhantes, os quais devem ser orientados/ capacitados sobre os cuidados que podem exercer com segurança, sem por em risco a vida do seu familiar.

Deste modo, a enfermagem deve estar sensível à presença deste familiar no hospital. E ste familiar busca, muitas vezes, superar as próprias dificuldades e limitações. Assim, a enfermagem necessita compreender as múltiplas situações imbricadas à hospitalização facilitando a expressão de diferentes sentimentos que as permeiam e a troca de informações indispensáveis e requeridas ao momento ${ }^{(18)}$.

O diálogo a seguir, no interior da dinâmica A Imanaque, revela a falta de comprometimento de alguns acompanhantes, no dia a dia dos sujeitos do estudo.

É que têm alguns que ficam mais no corredor, na televisão, que cuidando do seu doente (E 4).

F azendo fofoca no corredor (T E 1).

Fazem o bolinho da fofoca (T E 8).

Ou reclamando de al guma coisa (E 4).

0 diálogo entre os membros da equipe de enfermagem demonstra que a conduta de determinados familiares acompanhantes gera desconforto na equipe, pois tumultua o serviço e compromete a recuper ação dos doentes. E $m$ alguns momentos, a convivência dos acompanhantes no cenário hospitalar, é vista como negativa. I sso ocorre quando eles trocam informações, compartilham experiências e, por vezes, elaboram opiniões e repassam boatos ${ }^{(19)}$. N esse caso, ao procurar os profissionais de saúde, esses familiares possuem uma atitude de cobrança ao invés de colaboração.

Por sua vez, é preciso que os profissionais da enfermagem estejam atentos à realidade sócioeconômica e cultural dos familiares acompanhantes. D everão atuar estabelecendo uma relação de confiança e de parceria, auxiliando a lidar com a situação de doença/ hospitalização e com as diferentes dificuldades objetivas e subjetivas relacionadas à dinâmica familiar e aos sentimentos desencadeados tanto nos acompanhantes quanto na totalidade da família que vivencia o processo de hospitalização e a presença da doença crônica em um de seus membros ${ }^{(18)}$.

\section{CONCLUSÕES}

F rente ao nível de dependência de cuidados dos doentes crônicos hospitalizados, o familiar acompanhante revela-se um importante aliado do cuidado. 0 estudo evidenciou que a equipe de enfermagem considera a presença do acompanhante indispensável para a recuperação dos doentes. A queles que não contam com acompanhantes, em geral, tornam-se apáticos, tristes e pouco colaborativos nos procedimentos. 
Os discursos desvelaram dificuldades para a inserção do familiar acompanhante no cuidado, relacionadas à singularidade de cada sujeito, no seu modo de agir, reagir e expressar-se neste ambiente, gerando muitos sentimentos, emoções e conflitos.

A falta de comprometimento dos acompanhantes foi evidenciada pelos sujeitos do estudo quando estes não comunicavam as alterações clínicas dos doentes, não permaneciam próximos a eles e não assumiam alguns cuidados. Deste modo, pode-se considerar que a inserção do familiar acompanhante no cuidado ao adulto hospitalizado é permeada de momentos, ora gratificantes, ora desgastantes para a equipe de enfermagem. U ma vez que, 0 acompanhante representa uma presença positiva quando contribui para o bem-estar físico, mental, social e espiritual do doente, assim como, alguém que al ivia e compartilha as atividades de trabal ho com a equipe. No momento em que 0 acompanhante não atende as expectativas da equipe de enfermagem, sua presença no ambiente hospitalar é consider ada negativa.

Conclui-se que é importante o reconhecimento da singularidade dos acompanhantes pel os profissionais de enfermagem, para que possam compreender suas idiossincrasias e assim inseri-los ou não nos cuidados, aceitando os limites e as possibilidades de cada um no processo de cuidar do doente.

\section{REFERÊ NCIAS}

1 Szareski C, Beuter M , Brondani CM . Situações de conforto e desconforto vivenciadas pelo acompanhante na hospitalização do familiar com doença crônica. Ciênc Cuid Saúde. 2009;8(3):378-84.

$2 \mathrm{~F}$ ranco $M C$, Jorge M SB. Sofrimento da família frente à hospitalização. I n: EIsen I, M arcon SS, Silva M RS. 0 viver em família e sua interface com a saúde e a doença. M aringá: E duem; 2004. p. 169-81.

3 M inistério da Saúde (BR). HumanizaSU S: Política N acional de Humanização: a humanização como eixo norteador das práticas de atenção e gestão em todas as instâncias do SU S. Brasília (D F ); 2004.

4 Squassante ND. A dialética das relações entre a equipe de enfermagem e familiares acompanhantes no hospital: implicações do cuidado de enfermagem [ dissertação] . Rio de Janeiro: U niver sidade Federal do Rio deJaneiro; 2007.
5 M inistério da Saúde (BR). Lei no 8.069, de 13 de juIho de 1990: dispõe sobre o Estatuto da criança e do adolescente e dá outras providências. Brasília (DF); 1990.

6 M inistério da Saúde (BR). Lei no 10.741, de 10 de outubro de 2003: dispõe sobre o Estatuto do I doso e dá outras providências. Brasília (DF ); 2003.

7 M inistério da Saúde (BR ). L ei no 11.108, de 02 de dezembro de 2005: dispõe sobre a permissão de acompanhante para a mulher em trabal ho de parto e no pós parto nos hospitais públicos e conveniados ao SU S. Brasília (DF); 2005.

8 Silva AM , Avelar M CQ. T he companion of the adult hospitalized patient: nurses' perception: a qualitative boarding [ Internet]. Online Braz J Nurs. 2009 [ cited 2009 Aug 20];6(3). Available from: http:/ / www.objnursing.uff.br/ index.php/ nursing/ article/ view/j.1676-4285.2007.1192/ 263.

9 Szareski C. 0 familiar acompanhante no cuidado ao adulto hospitalizado na per spectiva da equipe de enfer magem [ dissertação] . Santa M aria: U niversidade Federal de Santa M aria; 2009.

10 Cabral IE 0 método criativo-sensível: alternativa de pesquisa na enfermagem. I n: Gauthier JH, Cabral IE, Santos I, T avares CM M , organizadores. Pesquisa em enfermagem: novas metodologias. Rio de Janeiro: Guanabara Koogan; 1998. p. 177-203.

11 Orlandi EP. A nálise de discurso: princípios e procedimentos. 7a ed. Campinas: Pontes; 2007.

12 M inistério da Saúde (BR), Conselho N acional de Saúde. Resolução 196, de 10 de outubro de 1996: diretrizes e normas regulamentadoras de pesquisa envolvendo seres humanos. Brasília (DF); 1996.

13 Lautert L, Echer IC, U nicovsky M AR. 0 acompanhante do paciente adulto hospitalizado. Rev G aúcha Enferm. 1998;19(2):118-31.

14 G omes G C, E rdmann A L . 0 cuidado compartilhado entre a família e a enfermagem à criança no hospital: uma per spectiva para a sua humanização. Rev $G$ aúcha Enferm. 2005;26(1):20-30.

15 Pena SB, D iogo M J D. Expectativas da equipe de enfermagem e atividades realizadas por cuidadores de idosos. Rev Esc Enferm USP. 2009;43(2):3517. 
16 Silva L, Bocchi SCM , Bousso RS. 0 papel da solidariedade desempenhado por familiares visitantes e acompanhantes de adultos e idosos hospitalizados. Texto Contexto Enferm. 2008;17(2):297-303.

17 Squassante ND, Alvim NAT. Relação equipe de enfer magem e acompanhantes de clientes hospitalizados: implicações para o cuidado. Rev Bras Enferm. 2009;62(1):11-7.
18 Beuter M , Brondani CM , Szareski C, Lana LD, AIvim NAT. Perfil de familiares acompanhantes: contribuições para a ação educativa da enfermagem. REM E: Rev M in Enferm. 2009;13(1):28-33.

19 Pereira M I M , G raças E M . A co-existência com familiares dos pacientes hospital izados: experiência do enfermeiro no seu mundo-vida profissional. REM E : Rev M in Enferm. 2003;7(2):93-101.

\section{Endereço da autora / Dirección del autor /} Author's address:

\section{Charline Szareski}

Rua José Jaconi, 610 , ap. 02, Centro

95020-250, Caxias do Sul, RS

E-mail: charlineszareski@yahoo.com.br
Recebido em: 15/ 06/ 2010

A provado em: 01/ 11/ 2010 